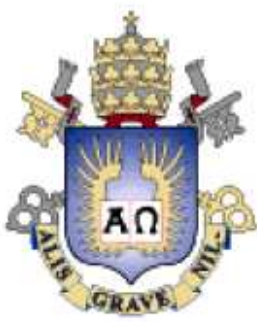

Bruna Teixeira Silveira

Estimativa de Pressão de Poros em 3 Dimensões

Dissertação de Mestrado

Dissertação apresentada como requisito parcial para obtenção do título de Mestre pelo Programa de PósGraduação em Engenharia Civil da PUC-Rio.

Orientador: Sérgio Augusto Barreto da Fontoura

Rio de Janeiro, abril de 2009 
Bruna Teixeira Silveira

\section{Estimativa de Pressão de Poros em 3 Dimensões}

Dissertação apresentada como requisito parcial para obtenção do título de Mestre pelo Programa de PósGraduação em Engenharia Civil da PUC-Rio. Aprovada pela Comissão Examinadora abaixo assinada.

Sérgio Augusto Barreto da Fontoura

Orientador

PUC-Rio

Franklin dos Santos Antunes

PUC-Rio

Luiz Alberto dos Santos Rocha

Petrobras

José Eugênio Leal

Coordenador Setorial do Centro Técnico Científico - PUC-Rio

Rio de janeiro, 02 de abril de 2009 
Todos os direitos reservados. É proibida a reprodução total ou parcial do trabalho sem autorização da universidade, da autora e do orientador.

\section{Bruna Teixeira Silveira}

Graduou-se em Engenharia Civil pela Pontifícia Universidade Católica do Rio de Janeiro em 2006. Em 2005 foi aluna de Intercâmbio Internacional na Universidade do Texas em Austin e atualmente trabalha no Grupo de Tecnologia em Engenharia de Petróleo da PUC-Rio como Especialista em Geopressões na companhia Petrobras. Principais áreas de interesse: Geomecânica do Petróleo, Mecânica de Rochas e Engenharia de Petróleo.

Ficha Catalográfica

Silveira, Bruna Teixeira
Estimativa de pressão de poros em 3 dimensões/
Bruna Teixeira Silveira ; orientador: Sérgio Augusto Barreto
da Fontoura. - 2009.
$\quad 96$ f. : il. ; $30 \mathrm{~cm}$
Dissertação (Mestrado em Engenharia Civil)-
Pontifícia Universidade Católica do Rio de Janeiro, Rio de
Janeiro, 2009.
Inclui bibliografia
1. Engenharia civil - Teses. 2. Pressão de poros.
3. Geoestatística. 4 . Modelagem geomecânica 5. Método
de Bowers. 6. Método de Eaton. I. Fontoura, Sérgio
Augusto Barreto da. II. Pontifícia Universidade Católica do
Rio de Janeiro. Departamento de Engenharia Civil. III.
Título.

CDD: 624 


\section{Agradecimentos}

Em primeiro lugar à Deus. Eu o louvo e agradeço por todos os dons concedidos, o dom da paciência com a dissertação e tudo que a envolveu, o dom da sabedoria concedido também com os estudos para a realização da mesma, o dom do discernimento de como conduzir essa atividade, todos os milhares de outros dons concedidos e principalmente o dom da fé de que Ele sempre esteve do meu lado em todos os dias dessa luta.

Agradeço o sim à Deus das pessoas que estiverem ao meu lado. A minha família como principal incentivadora desse mestrado. Minha mãe que praticamente fez de tudo pra eu tomasse a decisão de hoje estar aqui e meu pai que sempre demonstrou a importância dos estudos em minha vida. À eles por aceitarem não ter a minha presença constante dentro de casa em favor da minha formação. E por todo o apoio financeiro e amizade que sempre tiveram por mim. Por todo o conhecimento que eles me passaram, pelo exemplo que sempre me deram e através desse exemplo me despetaram a vontade de seguir a mesma carreira de geotécnica.

Agradeço também a toda minha familia. À minha querida vozinha Egle que eu tanto sinto não poder ir mais ve-la todos os dias em sua casa. Por todas as ligações sempre preocupada comigo. A minha querida madrinha Kathia e minha prima Ana Carolina. E claro, aos meus grandes irmãos, o Renan que sempre foi meu grande companheiro e esteve comigo durante esses duros anos de estudo e a minha irmã Paula, agradeço por existir e peço desculpa por não te-la visto crescer.

O agradecimento aos meus amigos que ao longo desses anos de estudo se tornaram minha familia. Às amigas Alice, Vivian, Bianca e Natacha, que foram as primeiras grandes amizades conquistadas aqui nessa cidade. À amiga Vivian 
Malta que sempre me ajudou muito. Aos amigos da pós Felipe, Raffaello e Arthur. Ao grande companheiro Saré por toda amizade e experiência dividida. Ao grande professor e amigo Claudio Amaral que sempre esteve ao meu lado e me apoiou muito em todas às minhas decisões, por todos os ensinamentos, longas conversas, caronas, chopps e oportunidades concedidas. Não poderia deixar de agradecer ao meu grande e amado mestre Franklin, nunca vou esquecer de sua felicidade ao me ver entrando nesse mestrado, seu abraço muito feliz e suas congratulações pela bolsa conquistada. A esses dois por me ensinarem a ser apaixonada pela Geologia como hoje sou.

Aos amigos da comunidade Gaudium Dei que me deram a oportunidade de voltar aos braços de Deus e porque através dessa amizade hoje eu conquistei a familia Chama de Amor. Por todas as crianças que ajudamos, pela Gaudium e os Irmãos de Fé que me mostrarem a importância de ajudar uma pessoa que não tem as mesmas chances que nós temos. Ao Chama querido, Guido e Thiago que o criaram, Marianna, Andrea, Simone, Nana, Dona Aurélia, Carlinha, Fernando, Fábio e Doug pela essa imensa amizade e por nunca me deixarem desistir. Aos meus sulistas preferidos, tia Cris e sua familia e a amiga Aline pelos nossos papos pelo telefone e internet. Aos amigos da Petrobras, João Paulo, Renata, Raquel, Rômulo e Gabriel, por todos os risos no momento de labuta, aos amigos do Gtep, em especial a Nelly e a Vivian, e aos amigos de Capítulo Estudantil da SPE. À todos os outros amigos por todo o apoio, amizade e compania.

Ao meu querido orientador Sérgio Fontoura, pelo seu exemplo, incentivo, amizade, conhecimento e compreensão. Por ser o orientador e chefe que é.

À Petrobras pelos dados concedidos para a realização dos estudos e a todos os engenheiros da Engenharia de Poço do ENGP, por todo o conhecimento dividido e seu incentivo. Em especial ao gerente Luiz Felipe, pelo amizade e incentivo e a Coordenadora Helena.

Ao Departamento de Engenharia Civil da PUC-Rio, ao GTEP, à SPE. Ao CNPQ, à CAPES e a PUC-Rio pelo apoio financeiro e tecnológico. 


\section{Resumo}

Silveira, Bruna Teixeira; Fontoura, Sérgio Augusto Barreto da. Estimativa de Pressão de Poros em 3 dimensões. PUC - Rio, 2009. 96p. Dissertação de Mestrado - Departamento de Engenharia Civil, Pontifícia Universidade Católica do Rio de Janeiro.

Nos projetos de engenharia de poço, o conhecimento das pressões é fundamental para o planejamento do poço e otimização do processo construtivo. Em geral, as estimativas de pressão de poros são feitas baseadas em análises unidimensionais de poços de correlação e dependem da experiência do analista responsável. Tais estimativas não contemplam todos os dados de uma região e muitas vezes dados não são bem aproveitados. Neste trabalho, é apresentada uma metodologia para estimativa de pressão de poros tridimensional, onde as propriedades dos poços da mesma região foram extrapoladas para toda área através da ferramenta geoestatística. A partir desta extrapolação, foi possível obter-se perfis sintéticos em qualquer locação dentro da região delimitada com maior confiabilidade, enriquecer a compreensão global da região modelada e finalmente construir um cubo tridimensional de pressão de poros utilizando os modelos de Eaton e Bowers, baseando-se no critério que a região apresenta a mesma tendência de compactação.

\section{Palavras-chave}

Pressão de Poros, Geoestatística, Modelagem Geomecânica, Método de Bowers, Método de Eaton. 


\section{Abstract}

Silveira, Bruna Silveira; Fontoura, Sérgio Augusto Barreto da (Advisor). 3D Pore Pressure estimation. PUC - Rio, 2009. 96p. Msc. Dissertation Civil Engineering Department, Pontifícia Universidade Católica do Rio de Janeiro.

The knowledge of pore pressures of rocks is critical to several aspects of petroleum the well design and planning. Usually, in the petroleum industry, estimations are based on 1D analyses of the analogues wells and depend on the professional experience. Moreover, estimations do not consider the whole base data of the field. In this dissertation, is presented a methodology for $3 \mathrm{D}$ pore pressure estimation, where well data is calculated for the whole area applying a geostatistical tool to build the 3D properties model. From that, it was possible to make more credible synthetics well logs at any location, enrich the whole area comprehension, and also, to build the pore pressure cube based on Eaton and Bowers pore pressure estimations models.

\section{Key-words}

Pore Pressure, Geostatistic, Mechanical Earth Model, Bowers Method, Eaton Method. 


\section{Sumário}

1 Introdução 17

$\begin{array}{ll}\text { 1.1. Motivação } & 17\end{array}$

1.2. Objetivo 19

1.3. Estrutura da dissertação 19

2 Revisão Bibliográfica $\quad 21$

2.1. Conceitos Básicos 21

2.1.1. Conceito de Sobrecarga 21

2.1.2. Conceito de Poro Pressão 23

2.2. Classificação de Pressão de Poros 25

2.2.1. Subpressão 25

2.2.2. Sobrepressão 26

2.3. Origem das sobrepressões $\quad 27$

2.4. Mecanismos geradores de sobrepressões 27

2.4.1. Mecanismos de tensões 27

2.4.2. Mecanismos de variação de volume nos fluidos 29

2.4.3. Mecanismos de movimentos de fluidos 29

2.4.4. Transferência Lateral e efeito centróide 31

2.4.5. Métodos de estimativa de poro pressão 31

2.5. Modelagem Tridimensional Geológica e Geomecânica (Earth Modeling) 38

2.5.1. Definição de Modelagem Geomecânica 40

2.5.2. Modelagem geomecânica (Cubo de pressão de poros) 41

3 Analise de dados 42

3.1. Descrição dos poços 44

3.1.1. Poços utilizados no modelo unidimensional (Poços de calibração)44

3.1.2. Poços utilizados no modelo tridimensional 49

3.1.3. Dados de entrada 50 
3.1.4. Modelagem geométrica

3.1.5. Modelagem de propriedades 58

3.1.6. Geostatística 62

4 Analise de Pressão de Poros 75

4.1. Gradiente de sobrecarga 77

4.2. Estimativa de pressão de poros utilizando o modelo de Eaton $\quad 80$

4.3. Estimativa de pressão de poros utilizando o método de Bowers 83

5 Conclusões e sugestões 87 


\section{Lista de figuras}

Figura 2.1 - Carregamento em material poroso. (Fonte: Teixeira et al. 2000) 23

Figura 2.2 - Blowout na Argélia (Fonte: Google acesso em 17/02/2009). 24

Figura 2.3 - Pressão em função da profundidade. 26

Figura 2.4 - Modelo de argilas saturadas (Fonte: Eaton, 1972) 26

Figura 2.5 - Subcompactação e expansão de fluidos (Modificado de Bowers, 2002) 28

Figura 2.6 - Efeito de tectonismo. (Modificada de Hudec M. R., Jackson P. A., 2007) 29

Figura 2.7 - Efeito Buoyancy. 30

Figura 2.8 - Transferência lateral de pressão. Dois poços perfurados atravessando o mesmo arenito. 31

Figra 2.9 - Traçado da tendência de compactação NTL em pontos de folhelho de acordo com o método de Eaton. 34

Figura 2.10 - Comportamento de compactação e expansão de fluidos. (Modificada de Bowers, 1995) 36

Figura 2.11 - Aplicação do método de Bowers. (Bowers, 1995) 38

Figura 2.12 - Cubo de Pressão de Poros estimado por (Modificado de Torres e $\begin{array}{ll}\text { Frydman ,2005) } & 40\end{array}$

Figura 3.1 - Padrões de litologia Petrobras $@$. 44

Figura 3.2 - Dados de poço DB-3. 46

Figura 3.3 - Dados do poço BD-4.

Figura 3.4 - Dados do poço DB-5. 48

Figura 3.5 - Dados do poço DB-11. 49

Figura 3.6 - Mapa de localização dos poços. 50

Figura 3.7 - Poços carregados no modelo e suas trajetórias. 51

Figura 3.8 - Construção de horizontes. 53

Figura 3.9 - Vista dos horizontes gerados.

Figura 3.10 - Divisão de camadas. 56

Figura 3.11 - Grid gerado. 
Figura 3.12 - Seção geológica construída. 57

Figura 3.13 - Corte transversal da seção apresentada na figura 3.12. 57

Figura 3.14 - Histograma de distribuição dos dados de perfis sônicos 59

Figura 3.15 - Processo de carregamento de dados na malha (upscaling). $\quad 60$

Figura 3.16 - Histograma de dados sônicos carregados no modelo comparado aos $\begin{array}{ll}\text { dados de perfis } & 60\end{array}$

Figura 3.17 - Dados de densidade carregados nas células do modelo. $\quad 61$

Figura 3.18 - Exemplo de semivariograma. 63

Figura 3.19 - Parâmetros de cálculo de semivariograma a partir de amostras irrergularmente espaçadas. (spud Camargo, 1997). 65

Figura 3.20 - Mapa Variograma de Raios Gamma. (Raio de busca $=3000 \mathrm{~m}$, número de lags 10).

Figura 3.21 - Mapa de variograma de Densidade (Raio de busca $=3500 \mathrm{~m} \mathrm{e}$ número de lags $=30$ ).

Figura 3.22 - Mapa de variograma de Sônico (Raio de Busca $=11000$ m e número de lags $=40)$.

Figura 3.23 - Semi-variogramas experimentais das amostras de dados sônicos e semi-variogramas com o modelo teórico exponencial. $\quad 68$

Figura 3.24 - Analise de dados - Transformação de tendência unidimensional e de escala.

Figura 3.25 - Variograma da propriedade sônico na zona 3 na menor direção. 70

Figura 3.26 - Análise estrutural de DT na zona 3. 71

Figura 3.27 - Histograma comparativo das etapas da modelagem de DT. 71

Figura 3.28 - Cubo de propriedade sônica.

Figura 3.29 - Cubo de propriedade de densidade. 73

Figura 3.30 - Cubo de propriedade Gamma Ray. 73

$\begin{array}{ll}\text { Figura 3.31- Validação dos resultados. } & 74\end{array}$

Figura 4.1 - Gráfico de tensão efetiva em função do sônico. 76

$\begin{array}{ll}\text { Figura } 4.2 \text { - Dados de MDT em função da profundidade. } & 78\end{array}$

Figura 4.3 - Perfil Densidade e gradiente de sobrecarga. 79

Figura 4.4 - Cubo de gradiente de sobrecarga. $\quad 79$

Figura 4.5 - Perfil sônico de folhelhos e tendência de compactação normal. 81

Figura 4.6 - Gradientes de pressão de poros e sobrecarga. 82 
Figura 4.7 - Gradiente de pressão de poros Eaton.

Figura 4.8 - Variação de tensão efetiva versus porosidade de acordo com o fenômeno de geração de pressão anormais (Yassir e Bell, 1996). 84

Figura 4.7- Estimativa de pressão de poros método de Bowers. 85

Figura 4.8 - Gradiente de pressão de poros Bowers. 86 


\section{Lista de tabelas}

Tabela 3.1 - Dados de topos estratigráficos. 


\section{Lista de símbolos e abreviaturas}

\begin{tabular}{|c|c|c|}
\hline & $S$ & Sobrecarga \\
\hline & $g$ & Aceleração da gravidade \\
\hline & $\rho_{b w}$ & Densidade dos sedimentos saturados \\
\hline & $D$ & Profundidade \\
\hline & $\rho$ & Densidade dos sedimentos \\
\hline & $\rho_{\text {matrix }}$ & Densidade da matriz \\
\hline & $\phi_{a}$ & Fração de porosidade dos sedimentos \\
\hline & $\rho_{w}$ & Densidade da água \\
\hline & $\phi_{b}$ & Porosidade dos sedimentos \\
\hline & K & Parâmetro empírico \\
\hline & depth & Profundidade \\
\hline & ppg & Libras por galão \\
\hline & $\sigma^{\prime}$ & Tensão efetiva \\
\hline & $\sigma t$ & Tensão total \\
\hline & $P p$ & Pressão de poros \\
\hline & $t$ & Tempo de trânsito \\
\hline$\frac{1}{2}$ & $R$ & Perfil resistividade \\
\hline & $\operatorname{PpN}$ & Pressão de poros normal \\
\hline 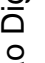 & $C$ & Perfil condutividade \\
\hline & $V$ & Velocidade (ft/s) \\
\hline & Vo & Velocidade no fluido \\
\hline & $A$ & Parâmetro de calibração \\
\hline & $B$ & Parâmetro de calibração \\
\hline & $\sigma_{\max }$ & Tensão efetiva no inicio do descarregamento \\
\hline & $V_{\max }$ & Velocidade no inicio do descarregamento \\
\hline & $U$ & Parâmetro de calibração de descarregamento \\
\hline & $\sigma_{v c}$ & Tensão onde a velocidade concorre com a curva virgem \\
\hline & Caliper & Perfis caliper \\
\hline & $G R$ & Perfis gamma ray \\
\hline & $D T$ & Perfis sônico \\
\hline & RHOB & Perfis densidade \\
\hline & $T F C$ & Dados de pressão medidos \\
\hline & $D B$ & Dom bosco \\
\hline & $M$ & Coeficiente angular da reta \\
\hline & $\Delta t$ & Intervalo de tempo \\
\hline & $Z$ & Profundidade vertical \\
\hline & $G_{o v}$ & Gradiente de sobrecarga \\
\hline & $\Delta t_{0}$ & Valor sônico no mudline \\
\hline
\end{tabular}


NTL Tendência de compactação normal

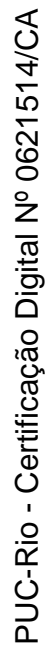

